\title{
Desafíos epistémicos en Nuestra América actual: organización, saberes y militancia ${ }^{1}$
}

\section{Epistemic challenges in our current America: organization, knowledge and militancy \\ Desafios epistêmicos em Nossa América atual: organização, saberes e militância}

\author{
Dra. Lorena González Fuentes²
}

Recibido: 29 de mayo de 2018 - Aceptado: 30 de julio de 2018

\begin{abstract}
Resumen:
El texto que se presenta a continuación busca evidenciar, desde el análisis del contexto nuestroamericano actual y el surgimiento de los Nuevos Movimientos Sociales, cómo se ha forjado una nueva forma política de construcción, que ha posicionado la producción de saberes como un elemento prioritario, conllevando el surgimiento de una nueva generación de militantes investigadores o intelectuales quienes, a partir de la praxis transformadora y de la mano de la Educación Popular, crean saberes y sentidos desde y para el fortalecimiento de la gesta liberacionista.
\end{abstract}

Palabras clave: Intelectuales - saberes - investigación militante - Nuevos Movimientos Sociales - Educación Popular

1 Este artículo forma parte de la investigación realizada en el marco de la tesis doctoral desarrollada por la autora "Configuración de una Epistemología Situada de la Resistencia: prácticas intelectuales y producción de saberes para la transformación social en Nuestra América", financiada por la Comisión Nacional de Investigación de Ciencia y Tecnología, CONICYT.

2 Chilena. Licenciada en Filosofía y Magíster en Filosofía Política y Axiología por la Universidad de Chile. Doctora en Estudios Americanos con especialidad en Pensamiento y Cultura, Universidad de Santiago de Chile. Actualmente se desempeña como académica en la Universidad de Santiago, la Universidad Católica Silva Henríquez y la Universidad Técnica Metropolitana. Educadora popular y militante del Colectivo Caracol, el apañe de los piños. Correo: lorena.gonzalez.f@usach.cl ORCID: https://orcid.org/0000-0002-6779-5552 


\begin{abstract}
:
From the analysis of the current American context and the emergence of New Social Movements, this text is aimed at showing how a new political form of construction has been forged positioning the production of knowledge as a priority element, entailing the emergence of a new generation of investigative or intellectual militants who, from the transformative praxis and the hand of Popular Education, create knowledge and meanings from and for the strengthening of the liberationist achievement.
\end{abstract}

Keywords: Intellectuals - knowledge - militant research - New Social Movements - Popular Education

\title{
Resumo:
}

O texto que se apresenta a continuação busca evidenciar, desde a análise do contexto nosso-americano atual e o surgimento dos Novos Movimentos Sociais, como se tem criado uma nova forma política de construção que tem posicionado a produção de saberes como um elemento prioritário, implicando o surgimento de uma nova geração de militantes pesquisadores ou intelectuais que, a partir da práxis transformadora e da mão da Educação Popular, criam saberes e sentidos desde e para o fortalecimento da gesta liberacionista.

Palavras-chave: Intelectuais - saberes - pesquisa militante - Novos Movimentos Sociais - Educação Popular

\section{A modo de introducción}

Se viven tiempos en los que el neoliberalismo ha calado no sólo en las lógicas de intercambio económico, sino que ha permeado intensamente todo tipo de instituciones. Los clásicos centros de producción de saber -las universidades y academias- no han escapado a esto. Por ello, cada vez es más radical la desvinculación de la producción teórica con la colectividad en la que se desenvuelve y, más aún, con los movimientos sociales que la circundan. No obstante, subyacen a los espacios institucionales y a las lógicas hegemónicas de la sociedad experiencias de resistencia, que forjan a pulso la construcción de un mundo otro y, para ello, reclaman nuevas concepciones, sentidos y saberes que fragüen esos vínculos 'otros', rehumanizadores, justos y dignos. Estas apuestas han debido asumir el déficit que los otrora intelectuales comprometidos han dejado. Es decir, han debido aprender a investigarse a sí mismos. 
Lo que se busca evidenciar en este escrito es cómo, a pesar de la invisibilización y a contrapelo de las validaciones y reconocimiento, existe desde los Nuevos Movimientos Sociales otra manera de producir, rescatar y socializar conocimientos, coherente con su apuesta ético-política, y que genera consecuentemente una nueva figura intelectual enraizada a la praxis constructora de un proyecto de liberación.

Para evidenciar esto, se problematizará cómo, en el contexto actual, ha tenido lugar el despliegue de los llamados "Nuevos Movimientos Sociales", dando cuenta de sus características y poniendo de manifiesto cómo, en su seno, se asume la construcción epistémica como una instancia de lucha prioritaria de la cual es imprescindible hacerse cargo.

\section{Nuestra América hoy}

Para comenzar, hay que tener a la vista algunos elementos que permiten comprender el funcionamiento y configuración del contexto actual, poniendo énfasis en cómo éste condiciona el despliegue organizativo. Se analizará esto considerando cuatro ámbitos, el económico, el político, el social y el cultural.

Desde la perspectiva económica, la agudización de la matriz neoliberal no sólo permea la esfera macro, sino que también se imbrica modificando el funcionamiento privado cotidiano. Respecto de esto último, en este escenario 'micro', el capitalismo se ha profundizado, pues ya no sólo genera su clásica plusvalía en función de la explotación, sino que ahora se ha creado una segunda fuente de enriquecimiento mediante el crédito y el endeudamiento sistemático al que los sujetos y sujetas deben recurrir para poder vivir. Esta doble plusvalía permite, por una parte, invisibilizar las consecuencias de la plusvalía originaria -en la medida en que es posible adquirir alimentos en un supermercado gracias a una tarjeta de débito y crédito $y$, con ello, disminuye el hambre en la población-y, por otra, la segunda plusvalía: al mantenerse oculta o disfrazada, no aparece en el espacio público oficial como conflicto estructural, por lo que no se vuelve fuente de descontento o crítica social, entonces domestica y desmoviliza (cf. Salazar 2012 220). De 
ahí que la pobreza y el pueblo sigan siendo un buen negocio para el neoliberalismo.

Por su parte, en la escena 'macro', es decir, yendo más allá de las implicancias que ha tenido la agudización de la matriz en el funcionamiento de los mercados locales y llevándolo al ámbito continental, se constata la apertura extractivista del modelo, mediante los Tratados de Libre Comercio, a los capitales transnacionales, quienes, por medio de sus corporaciones, saquean sistemáticamente los recursos naturales -convertidos en mercancías de alto valor especulativo-, desplegando una serie de innovaciones tecnológicas destinadas a la eficacia predadora. Proliferan, entonces, volviéndose elementos constitutivos de la postal nuestramericana, el asentamiento de monocultivos y transgénicos (cuya figura emblemática es Monsanto Company), la lucha por los hidrocarburos (Chevron Corporation) y la megaminería (Barrick Gold Corporation, BHP Billiton, etc.), con todo lo que eso implica para la población y la tierra donde tienen lugar. Es decir, exposición a agrotóxicos, usurpación del agua, contaminación, construcción de centrales energéticas destinadas a abastecer a las mineras, pérdida de derechos comunales, desplazamiento forzoso de las colectividades originarias, ya que sus territorios son usurpados en pos de facilitar estas lógicas de extracción, etc.

Esta nueva faceta del imperialismo, que el geógrafo David Harvey denomina "acumulación por desposesión", tiene la particularidad de ya no utilizar exclusivamente la generación de crisis financieras para, a través de la especulación, perpetrar el despojo; sino que se flexibiliza y diversifica. Sus mecanismos se pluralizan abriéndose a nuevas dimensiones antes impensadas, tales como los derechos de propiedad intelectual que se traducen -de la mano del cuestionado acuerdo Transpacífico de Cooperación Económica (TPP)- en patentar los procedimientos médicos o, incluso, las semillas; o la mercantilización de la cultura; o la privatización de derechos básicos que antes eran públicos (universidades, salud, el agua, el mar, etc.), generando, como indica Harvey, un "cercamiento de los bienes comunes" (114).

En este sentido, menciona Raúl Zibechi (2011a), "el capital subió un escalón y se convirtió en capital especulativo. Se especula con el oro, 
con la plata, con la tierra, con el agua; es decir, se especula con la vida". Así es como, por paradójico que parezca, el enemigo real de esta cruzada es la humanidad, ya que es la única capaz de hacerle frente al enriquecimiento de los magnates del centro a costa de la vida y dignidad de los muchos y muchas en los márgenes. Poniendo atención al funcionamiento y consecuencias del neoliberalismo extractivista, Ramón Gómez Medero (cf.) explicita que la implementación de éste no sólo conlleva la modificación de la matriz productiva, sino que trastoca el entramado de relaciones en todos los niveles posibles. Cabe mencionar que todo esto se implementa y consolida con la venia de los Estados y sus gobiernos, más allá de la perspectiva política con la que se cuadren. "Sostenemos -afirma el sociólogo y educador popular argentino Roberto Iglesias- con absoluta firmeza que los gobiernos de América Latina, en términos generales, están al servicio y participan aunque sea con migajas de esta expropiación" (42). Por ello, los movimientos políticos y sociales actuales se manifiestan abiertamente contra los Estados y su papel como aval y cómplice de la acumulación por desposesión.

En directa relación con esto y pasando al ámbito político, los sistemas democráticos también se han vuelto un estorbo y, por lo mismo, el capital transnacional, cuando es desafiado o el gobierno de turno pone en jaque alguno de sus planes y aspiraciones, encuentra el modo de desestabilizarlo, ya sea a través de la intervención y sabotaje -Venezuela- o de la destitución directa -Manuel Zelaya en Honduras el 2009, Fernando Lugo en Paraguay el 2012 y Dilma Rousseff, en Brasil, el 2016, para quien, hasta hoy, no se encuentran pruebas reales y fidedignas que respalden las acusaciones de corrupción que "justificaron" su destitución-. De ahí que, como indica Boaventura de Sousa, nuestra actualidad política está determinada por sociedades que estarían experimentando un nuevo tipo de fascismo pluralista, capaz de coexistir con una democracia política liberal (cf. 36).

Entonces, las "democracias" imperantes, serviles al imperialismo extractivista, funcionan imponiendo un "consenso" que se sostiene sobre la base de la invisibilización de la discordancia y de la movilización popular, acompañado de una "obstaculización del acto y la 
expropiación de las potencias populares" (Colectivo Situaciones 2001 29). Este modo de funcionamiento, trascendiendo las intenciones o lo que discursivamente se declare, lo han asumido de manera transversal tanto los gobiernos conservadores de la región, como los llamados "progresistas". En relación a estos últimos, más allá de los balances, distanciamientos y aportes que se pudieran establecer de cada una de estas administraciones, hay dos elementos que es pertinente señalar.

El primero se vincula con cómo la gestión progresista ha generado un desgaste en los espacios organizativos de base, ya sea porque muchos de ellos se sumaron al proceso gubernamental creyendo en la apuesta y después se vieron cooptados, y frente a la traición de la que fueron víctimas a través de la mercantilización de sus demandas, nuevamente han caído en el fatalismo y desesperanza. O porque nunca se creyó en la propuesta y se siguió trabajando a contrapelo, en una invisibilización aún mayor o tras la estigmatización de ser radicales, de "hacerle el juego a la derecha" con sus extremismos y posturas "ultronas", conllevando el menosprecio o puesta en duda de todo el trabajo, apuestas y experiencias gestadas y acumuladas. Al respecto, los situacionistas establecen -en medio del kirchnerismo- que la consecuencia de la deficiencia del progresismo es lo que denominan el "impasse político y social", producido por el debilitamiento de las tendencias más virtuosas que caracterizaron a la nueva gobernabilidad, bloqueando su espíritu innovador, y dando lugar así a un tiempo de "atoramiento" en el que se estaría inmerso (cf. Colectivo Situaciones 2009 21).

El segundo elemento se relaciona con cómo el despliegue e instauración de estas administraciones ha propiciado una inflexión en la praxis de los actores políticos y sociales, en la medida en que se produce un quiebre radical con el paradigma estratégico "clásico" a seguir. Es decir, aquél que lucha por la toma del poder del Estado. En la medida en que se fractura esta apuesta, se renuncia también a avalar la adopción de una serie de formas estadocéntricas de organización, tales como el centralismo, la división entre dirigentes y dirigidos y la distribución piramidal del funcionamiento (cf. Zibechi 2007 98). 
El distanciamiento respecto de esta apuesta exige asumir posiciones, catalizando, entonces, la visibilización y radicalización de la praxis liberacionista, Ilevándola a cuestionarse por sus formas, principios y proyectos. Esto se expresa con fuerza en aquellos sujetos, organizaciones colectivas o comunidades humanas que se sitúan en los ribetes subterráneos de la sociedad, en los márgenes de lo instituido, en lo que Luis Tapia ha denominado el "subsuelo político", el cual es configurado por "aquello que no es reconocido en la superficie de la sociedad, porque es feo, inútil, atrasado, disonante, disfuncional, conflictivo o incomprensible. El subsuelo es el margen más o menos amplio de los no reconocimientos o desconocimientos que existen en un país o sociedad" (96)

Lo interesante de este espacio es que al encontrarse "fuera" de los cánones oficiales, no ha sido formateado del todo por la inercia, inmovilidad y automatización que desde el poder se imponen sobre las subjetividades. Por lo mismo, más que ser un espacio de delincuencia, horror y monstruosidades, es un espacio de creatividad, de ensayos y experimentación, en dónde existe la posibilidad de construir cosas nuevas. Son espacios fragmentarios de vida colectiva y comunicación intersubjetiva que surgen como alternativa al monopolio político de los partidos y el Estado (cf. Tapia 107).

El subsuelo es el espacio donde se gesta resistencia frente al ninguneo, invisibilización y opresión de los poderosos y sus gobiernos. Es el territorio de la organización y creatividad colectiva. Es la instancia desde la que surgen y se fraguan apuestas ético-políticas transformadoras, y que, antes del desborde, se filtran en actividades, marchas o manifestaciones populares dotándolas de sentido, al mismo tiempo que se construyen nuevas. Si en un lado de la sociedad las elites empresariales se asocian al capital transnacional, en "los abajos" se potencian las creaciones alternativas y contestatarias que se embarcan en una guerrilla cultural -contrahegemónica- frente a lo imperante. En estos terrenos subterráneos se acumulan fuerzas, ensayos y experiencias, a tal punto que, llegado el momento, se produce el desborde. Se reclama y exige la visibilidad, el reconocimiento y/o legitimación como alternativa válida. Es la soberanía 
popular que se expresa volviéndose fuerza constructora de realidad (cf. Salazar 2012 227).

Así es cómo nos adentramos en el ámbito de lo social como tercer eje para comprender la situación actual. Y, en específico, dentro del espectro social, lo que se relaciona con el surgimiento de movimientos sociales que rompen con el repertorio tradicional de funcionamiento, acción y proyecto. Estos movimientos sociales, surgidos en las postdictaduras y tras la instalación de la matriz neoliberal en la región, transitan por nuevos caminos, en las fisuras que han ido creando en el modelo de dominación. Estas son

las respuestas al terremoto social que provocó la oleada neoliberal de los ochenta, que trastocó las formas de vida de los sectores populares al disolver y descomponer las formas de producción y reproducción, territoriales y simbólicas, que configuraban su entorno y su vida cotidiana (Zibechi 2007 97).

Estos movimientos sociales ${ }^{3}$ cuentan con tres antecedentes o influencias que desde ellos mismos se busca rescatar. Estas son las comunidades eclesiales de base que hicieron carne la teología de la liberación; la insurgencia indígena con su cosmovisión distinta a la eurocéntrica; y el guevarismo no tanto desde la estrategia guerrillera, sino desde la propuesta de hombres y mujeres nuevas forjadas mediante una militancia revolucionaria profundamente ética, pedagógica y humana (cf. Zibechi 2007 97). Son movimientos que, por lo mismo, a pesar de sus diferencias y particularidades, tienen una impronta antipatriarcal, anticolonialista y antiimperialista.

\footnotetext{
3 Entre ellos cabe destacar, de manera emblemática -no sólo por el impacto que han tenido o por el tiempo que llevan resistiendo, sino porque efectivamente han forjado una forma de vida integral (contemplando salud, educación, vivienda, economía, política, construcción ética y cultural, cosmovisión y saberes) que rompe, perdura y desafía los cánones impuestos por la maquinaria imperialista neoliberal-al Movimiento Sin Tierra en Brasil, al neozapatismo (Ejército Zapatista de Liberación Nacional) en tierras chiapanecas. Y también, cabe señalar a los indígenas ecuatorianos, los guerreros y guerreras del agua, el movimiento de desocupados en argentina, entre otros.
} 
A partir del accionar político de los movimientos sociales y de cómo su apuesta abandona la idea de transformar el mundo, y se centra en la posibilidad de construir otro(s) nuevo(s), se han vuelto fundamentales tres aristas articuladoras de su despliegue. Estas son la relación con el territorio, la autonomía y la vinculación con el Estado.

El territorio se vuelve un eje fundamental pues, mediante su control, es posible gestar la producción y satisfacción de las necesidades populares sin recurrir a lógicas peticionistas, sin depender de la caridad y migajas con las que el poder opresor desestabiliza y domestica las revueltas sociales. En la medida en que se posee un territorio, se recupera la autoproducción de la vida, no sólo desde el punto de vista economicista. "El territorio es el espacio en el que se construye de forma colectiva una nueva organización social, donde los nuevos sujetos se instituyen, instituyendo su espacio, apropiándoselo material y simbólicamente" (Zibechi 2007 104). Por eso, se apuesta a la territorialización mediante la recuperación o conquista de inmuebles (escuelas, casas, fábricas, etc.), fundos, predios, plazas, entre otros.

Teniendo a la vista este elemento, es posible comprender por qué la autonomía se vuelve central. En la medida en que se posee y se produce un territorio, se vuelve viable la autogestión material y simbólica de las propias vidas. De este modo, se le arrebatan al capital los cuerpos y subjetividades, y se opta por forjarlas desde otro lugar, con lógicas distintas, potenciando la capacidad creadora y las realizaciones comunitarias. La construcción de un mundo otro demanda poder producir la existencia desde todos los ámbitos. Es decir, desde los más básicos y materiales (pan, techo, abrigo), que permiten la subsistencia, hasta los que se vinculan con el desarrollo de las potencialidades y capacidades, vale decir, con aquello que nos hace volvernos sujetas y sujetos íntegros, poseedores de una vida digna. Entonces, la autonomía también implica la afirmación y recuperación de una cultura e identidad diversa pero común, convocante y movilizadora, en la que nos reconozcamos como artífices protagonistas de esa historia y memoria popular, tantas veces silenciadas por las versiones oficiales o por las apuestas revolucionarias eurocéntricas que menospreciaban las particularidades culturales que tiene Nuestra América. La autono- 
mía exige resignificarse, recordar y construir tanto narraciones como referentes y aspiraciones propias, sin depender de las instituciones del poder que buscan inmiscuirse o determinar las decisiones y proyectos, condicionando su financiamiento o posibilidad de existencia.

Territorio y autonomía es lo que posibilita que estos movimientos no sean sólo un desborde político fugaz, que es rápidamente neutralizado o reprimido y debe volver a resguardarse en el subsuelo. La resistencia materializada en la autoproducción autónoma del territorio y la vida permite que los movimientos sociales quiebren con la naturalización del sistema y demuestren, ya no discursiva o lógicamente sino en la práctica concreta, la posibilidad, el germen de un mundo otro. Así, estos movimientos desarrollan, dentro del capitalismo, zonas o lugares donde la vida no está regida por él (cf. Benasayag 62), desplazando la frontera de lo viable, ampliando el horizonte de lo posible (cf. Iglesias 33).

Al tener en consideración todo esto, la manera en que estos "territorios en resistencia" (Zibechi 2009) se relacionan con el poder no causa gran extrañeza. Como ya se ha mencionado, la toma de poder estatal no es la ruta a seguir o, al menos, no como apuesta central. Llegar al podio gubernamental no es el móvil o el objetivo; por eso, conseguirlo no es vencer. "La revolución -indica John Holloway-es necesario concebirla en otros términos: no como la toma del poder sino como la disolución del poder" (2001 75).

El Estado, con sus lógicas y modos de funcionamiento, es el lugar donde el poder ${ }^{4}$ se vive como potestas, poder-sobre. Por ello, su despliegue implica la inhibición de la capacidad creadora, de la espontaneidad y potencialidad de los sujetos y sujetas. Es una estructura intrínsecamente opresora, que ha sido diseñada por los poderosos y perfeccionada por la oligarquía con el paso de la historia para mantenerse en ese lugar, garantizando la perpetuación de sus privilegios. Por ello, todo proceso de transformación que se impulse desde este

$4 \quad$ Respecto a la distinción entre poder como potestas y poder como potentia, ver Dussel (2006 27-33). 
lugar genera paradojas, contradicciones y fracasos históricos; así, se vuelve un espacio de desconfianza. La historia reciente y también las reflexiones ponen en evidencia que no es posible gestar una sociedad otra, autodeterminada, utilizando un instrumento que fue creado para reprimir esa autodeterminación. Por ello, afirma Holloway (2012), "No es posible la transformación radical de la sociedad a través del Estado" (44).

La creación de un mundo otro en el que todas y todos sean protagonistas no puede apostar a conseguirse a través de una estructura cuyo funcionamiento se sostiene precisamente en lo contrario. Más que concentrar el poder en un sólo lugar o instrumento, lo que se pretende es diversificarlo, irradiarlo, difundirlo. Lo que se busca es el empoderamiento integral de las bases, no la delegación y canalización de éstas a través de un representante. Al respecto indica Benasayag: "No se trata de negar la utilidad de los organismos e instancias de gestión y coordinación; simplemente es hora de tomar en cuenta el hecho que toda ambición de poder, todo deseo de poder, va inmediatamente acompañado de una pérdida de potencia de las experiencias reales" (64).

De este modo, frente a lo que tiene instituido, la política en los movimientos sociales se resignifica como espacio de disputas donde la existencia es recuperada, donde se valora la diversidad y las riquezas que entregan las experiencias particulares, y donde la clave no es el punto de llegada, sino el "proceso" para conseguirlo. En la misma línea, Ana Esther Ceceña añade:

Cuando no hay proyectos sino horizontes, cuando como hoy, lo urgente requiere tiempo y paciencia porque exige la refundamentación de la vida y la comunidad, cuando el objetivo es el camino, porque para los revolucionarios y soñadores, en rigor, nunca hay punto de llegada, la política es un espacio de disputa en el que, rompiendo normas y fronteras, la sociedad vuelve a existir (71).

Y frente a todo esto, ¿cuál es el rol o lugar que ha desempeñado el pensamiento crítico latinoamericano, sobre todo si se tiene en cuenta 
que, en su ejercicio, las mismas organizaciones, comunidades o movimientos han ido reflexionando sobre su andar, generando preguntas y soluciones que han nutrido, consecuentemente, su praxis?

Desde el ámbito cultural -el cuarto eje a tener en consideración-y en específico desde la construcción de saberes, en este contexto hay que partir constatando que históricamente el continente ha sido pensado por un sujeto predominante, quien se ha establecido como el autorizado para este tipo de labor. Como sostiene la educadora popular argentina Claudia Korol: "El continente es pensado desde una voz principal, a partir de un sujeto hegemónico: burgués, blanco, masculino, urbano, heterosexual. El resto -la mayoría- es el otro: el bárbaro, primitivo, negro, indio, mujer, homosexual, pobre, extranjero/a" (345). Y a partir de este sujeto y la construcción e imposición de su cultura se genera un sentido común servil a la ideología dominante, que se inscribe en nuestros cuerpos y afectividades. La introyección del opresor implica asumir sus cánones culturales, por eso no es raro que en el estudio de las humanidades o el arte haga más sentido viajar a Europa a aprender in situ en la "cuna de la civilización", que reconocer y sumergirse en la ancestralidad, cosmovisión y conocimientos forjados en nuestras latitudes, tanto por sus habitantes originarios como por los mestizos. Así, la cultura de la violencia vencedora se impone como dominación y como sentido común -tal como lo diagnosticaba Gramsci-; entonces, la colonización no es sólo la ideología del poder, sino también la validación de éste en nuestros cuerpos, afectividades, sentidos, etc. (cf. Korol 346).

A esto hay que agregar lo que el capitalismo ha hecho con el saber y la cultura. Por medio de su mercantilización, ha ido "despolitizando" el lenguaje, vaciándolo de contenido, estereotipándolo o cooptándolo, al mismo tiempo que se menosprecia el crear comunitario y se vuelven preponderantes y valorables las creaciones individuales, fácilmente atribuibles a la excepcionalidad de un sujeto particular aislado del mundo, que no responde a los intereses ni necesidades de la colectividad en que se desenvuelve. De este modo, la palabra deja de ser enunciada para propiciar la apertura de la imaginación colectiva y se vuelve otro instrumento más desde donde justificar las jerarquías actuales (cf. Colectivo Situaciones, 2009). 
Como producto histórico de su tiempo, ni el espacio académico o universitario ni sus críticos intelectuales escapan a estas directrices $y$, al verse influenciados por todo esto, se quedan sin muchas herramientas con las cuales hacer frente al sistema, sobre todo porque, más allá del ejercicio reflexivo, no tienen una práctica coherente rebelde y contestataria. De ahí que Zibechi \& Machado adviertan que los intelectuales orgánicos de hoy se desentienden de esa impronta crítica y autónoma, y buscan acomodarse en los espacios de legitimación que en la actualidad existen. Entonces, términos como "revolución", "socialismo" y "patria grande" se vuelven muletillas que les permiten pronunciar discursos que avalen administraciones progresistas y sus liderazgos institucionales (cf. 167).

A pesar de esto o más allá de cómo se despliega la práctica reflexiva, prevalece la necesidad de reposicionar el pensamiento en tanto trinchera de lucha, como una manera de hacerle frente a la agudización de la dominación capitalista en la esfera cultural e ideológica. Como indica Atilio Borón, "creo que es oportuno recordar aquella frase tan sabia de Martí, cuando decía, de pensamiento es la guerra que se nos hace, ganémosla a pensamiento" (35). E incluso, hay sujetos que van más allá y establecen la necesidad de que el intelectual se sumerja en el hacer de los espacios organizativos y militantes para potenciar la gestación de una cultura y estrategia comunicativa propia, diluyendo la exclusividad de su función en la asunción de la misma por parte de la colectividad. Como cuestiona Mazzeo:

¿Por qué en vez de oficiar de "puente", el intelectual no asume directamente las tareas militantes en el proceso de construcción colectiva de instrumentos políticos propios de las clases subalternas, fomentando la autoestima y la solidaridad del colectivo social? [...] ¿Por qué en lugar de asumir las funciones del "visibilizador" (y del intérprete) de una comunidad, el intelectual no aporta a un proceso de 'autovisibilización' de esa comunidad? (77).

De manera incipiente, a partir de las recientes citas, es posible identificar dos maneras de concebir el ejercicio de pensamiento crítico en un contexto como el nuestro. Si bien ambas comparten la premisa 
respecto a que la construcción de una realidad otra necesita también de la creación y visibilización de una cultura y saberes coherentes, se diferencian en cómo dichos conocimientos son gestados y socializados y el significado que tienen en la lucha, lo cual se relaciona estrechamente con la manera en que buscan lograr la revolución. Es decir, la diferencia es, nuevamente, metodológica, lo que a su vez pone en evidencia la perspectiva política en que se inscribe.

Mónica Iglesias trabaja con esta diferenciación, proponiendo la existencia de dos corrientes en el pensamiento crítico latinoamericano de la etapa actual, las que denomina "autonomista" y "contrahegemónica". Esta última se resiste a abandonar el tradicional modo de revolución; entonces, persevera en su apuesta por la toma del poder del Estado. En dicho proceso, la producción intelectual debe estar al servicio de forjar una propuesta hegemónica transformadora, de modo que, cuando se consiga llegar al gobierno, los militantes, organizaciones y movimientos se institucionalicen, fomentando a través de una cultura revolucionaria las modificaciones y reformas. En este sentido, esta corriente se encuentra fuertemente influenciada por la propuesta gramsciana respecto del rol que la cultura, la educación y los saberes desempeñan en la construcción de una realidad otra. Y la intelectualidad, en ese caso, sería la responsable de fraguar el espíritu de esta nueva sociedad. Por lo mismo, el ámbito intelectual de la lucha se vuelve prioritario y garantía de perduración o subsistencia de la gesta transformadora. Como indica Atilio Borón, emblemático exponente de esta corriente, "tenemos que vencer primero la batalla de las ideas y después vendrán las otras, porque si no vencemos la batalla de las ideas, los triunfos que podamos obtener en el terreno político, o militar o económico, van a ser triunfos efímeros y pasajeros" (36).

Frente a esta corriente, que se sitúa en los espacios académicos e institucionales, aparece la otra, es decir, la autonomista, cuyo lugar de reflexión y creación está en los márgenes y fisuras, en el seno mismo de las organizaciones políticas y sociales. Los que, aunque no cuenten con el prestigio y tribuna que los primeros poseen, producen teoría crítica que enriquece y potencia la resistencia que las moviliza. 
Cabe mencionar que, desde la corriente autonomista -que seguiremos desarrollando en lo que sigue de este escrito, pues en ella se sitúa esta nueva generación de investigadores e investigadoras militantes-, existe una crítica aguda y profunda a las formas intelectuales clásicas o propias de la apuesta institucional, cuyo centro se articula en torno a cómo estas maneras de generar conocimientos caen en lógicas castradoras y reductoras de las experiencias, precisamente por no tener una práctica real -más allá de la que supone el ejercicio especulativo o teórico- que la alimente o motive. Entonces, al no tener como punto de partida la praxis situada, se terminan imponiendo reflexiones conservadoras (cf. Colectivos Situaciones 2009).

Aunque la corriente contrahegemónica pretenda reconocerse heredera de la filosofía de Gramsci, para la perspectiva autonomista esto es un error y, más que corresponder a la tradición del intelectual orgánico, establece que el modo de funcionamiento de los intelectuales de izquierda cae en la concepción croceana, idealista. Por ello, diagnostica Mazzeo, asumen que la batalla de las ideas es prioritaria y, por eso también, se atribuyen a sí mismos un sitial imprescindible en la lucha. Como indica el militante argentino, "aunque este intelectual lo niegue, cada vez que se le presenta la oportunidad, no deja de concebirse como el conductor de la historia y considera que el terreno en el que se libra la batalla más significativa es un terreno de ideas, cultural, no político" (Mazzeo 96).

Tal como antaño, la apertura del mercado permitió que los intelectuales se independizaran de las cortes, pudiendo asumir posiciones políticas o trabajar temáticas propias; hoy por hoy, los avatares mercantiles, a través de la ampliación de la oferta de centros de formación y la posibilidad de endeudamientos eternos, han permitido que las capas populares puedan entrar a las universidades sin perder el vínculo con sus sectores de procedencia. De este modo, los movimientos sociales se han ido nutriendo a partir de la formación, capacidades y conocimientos que sus propios sujetos han aportado, propiciando así que las organizaciones tengan hoy la capacidad de crear sus propios intelectuales, con criterios pedagógicos propios, que se inscriben en la lógica de la educación popular, dejando atrás aquellos tiempos en 
que intelectuales ajenos al movimiento hablaban por él (cf. Zibechi 2007 101).

La práctica política presenta desafíos: “ ¿Cómo contribuir a esa lucha de la realidad por convertirse en pensamiento?" (Mazzeo 99), es uno de los que esta tendencia -la autonomista- ha asumido, no por pura presunción, sino porque a partir de los espacios organizativos se ha desvelado como necesario para consolidar y potenciar las prácticas autogestivas de resistencia. Esta aspiración -el mejoramiento y despliegue de los haceres transformadores- es el nudo articulador en torno al cual se gesta y hace sentido cualquier reflexión o análisis que se produzca desde los territorios autónomos y rebeldes. $Y$ desde allí la teorización se vuelve una herramienta fundamental en la acción revolucionaria.

A partir de esta situación, con sus provocaciones y cuestionamientos, surge una nueva generación intelectual, poniendo de manifiesto que el movimiento popular ya no necesita de teóricos externos que vengan a explicarle cómo, por qué y para dónde avanza. Tampoco que vengan a nombrar sus haceres y experiencias. La generación de saberes situacionales no depende de técnicos sabihondos, sino de la posibilidad que la organización tenga de producir sus propias reflexiones (cf. Colectivo Situaciones 200121 ).

\section{Surgimiento de una Nueva Generación}

A pesar de la desarticulación del tejido social que lograron las dictaduras cívico-militares, esta trama se fue volviendo a entretejer, lentamente y a pulso, ya sea a partir de la necesidad de satisfacer carencias básicas -tales como la alimentación, cuidado de los niños y niñas, la vivienda, cómo enfrentar la represión, etc.- , como también, al ir generando espacios de encuentro, discusión y creación cultural y educativa con otros y otras -centros culturales, talleres para jóvenes y adolescentes, escuelas de nivelación de estudios, bachilleratos populares, bibliotecas populares, preuniversitarios, etc.-. Esta red que lentamente se va fraguando tiene puntos álgidos de visibilización y desarrollo en función de las circunstancias políticas y sociales que en el contexto van teniendo lugar, las cuales exigen que estos espacios 
comunitarios expandan al máximo su capacidad de acción e impacto, pues, en situaciones de crisis, el subsuelo se desborda y se vuelve viable profundizar las grietas del sistema, denunciando -y apostando a transformar- la miseria e injusticia que engendra. Ejemplos de esto son la crisis argentina vivida el 19 y 20 de diciembre del 2001, o la serie de movilizaciones estudiantiles que, en Chile, desde el Mochilazo de 2001, han tenido lugar.

A partir de "hitos" como estos - precedidos por la maduración y consolidación de los colectivos y organizaciones-, y en función de las consecuencias que tuvieron, es posible identificar el surgimiento de una nueva generación intelectual, que se diferencia de los clásicos teóricos comprometidos o revolucionarios y que se distingue por un tipo de praxis y sensibilidad propia, que se genera desde el hacer transformador, desde la militancia. Como dice Mazzeo, "una nueva generación intelectual radical, crítica, impregnada de una subjetividad de la insubordinación, con vocación emancipatoria, es decir, una nueva generación intelectual 'militante'" (16). Cabe mencionar que, al hablar de "generación", no nos referimos a un grupo humano que comparta la misma edad sino que, como agrega el pensador argentino: "El concepto de generación va mucho más allá del conjunto de coetáneos. Por cierto, el término generación también remite al acto de engendrar" (Id. 32)

Para comprender en qué consiste esta nueva generación, y cuáles son sus particularidades y apuestas que la hacen diferenciarse de otras, hay dos elementos catalizadores que hay que tener en cuenta. Estos son, la socialización de la producción de conocimiento y las posibilidades que entrega el desarrollo tecnológico mediante las redes sociales.

Respecto de lo primero, ¿a qué nos referimos cuando decimos que la producción de saber se ha socializado? Básicamente, a aquello que fue enunciado tangencialmente en el apartado anterior, a propósito de cómo los sujetos y sujetas populares han podido ingresar a espacios de formación que antes eran exclusivos de la clase acomodada. Esto ha generado un cambio histórico del contexto intelectual, trayendo como consecuencia que tanto el intelectual como su labor se hayan des-elitizado. En la era de la "universidad de masas", el teórico ya 
no es un sujeto que pertenece a la clase exclusiva, cuya riqueza no es necesariamente material, sino simbólica, por tener el monopolio del saber. Ahora la noción de intelectual se ha ampliado, pues un periodista, un profesor o un universitario pueden ser llamados "intelectuales" sin que eso signifique privilegio alguno (cf. Traverso 55). Es decir, podríamos establecer que la intuición de Gramsci acerca de que todos y todas somos filósofas o teóricas ha sido encarnada por todas aquellas personas que, transgrediendo los mandatos de la elite, osan a formarse y desempeñar esas funciones que antes eran privativas. Así, la producción del saber deja de ser concesión de unos pocos y se vuelve una herramienta o práctica que se masifica y, entonces, puede ser realizada por sujetos y sujetas comunes quienes, desde una perspectiva crítica, no buscan reproducir las temáticas y cuestionamientos que desde lo imperante se imponen, sino que apropiándose de lo aprendido se vuelven sobre las preguntas y necesidades de su clase. Es decir, se comenzó a hacer ciencia popular en la que el pueblo se investiga a sí mismo (cf. Salazar 2011 23).

Al asumir esta capacidad, se accede a una autonomía cultural y epistémica que antes no existía. Por lo mismo, si ya existía una desconfianza en el vínculo que los intelectuales generaban con los movimientos populares -la que no era azarosa ni un mero capricho, sino que se fundamentaba en que, al ser una figura externa, los teóricos traían influencias que no eran propias del espacio organizativo, forzando y negando los propios procesos de reflexión que se generaban ahí mismo-, ahora se acrecienta en la medida en que dejan de ser necesarios y que, al descubrir una manera otra de crear saberes, se identifica al intelectual clásico como "el representante de un pensamiento y actitudes pequeño burguesas" (Campione 52), es decir, que le "falta calle" y que, por lo mismo, desde la calidez de su biblioteca no conoce la realidad de aquellos que pretende ilustrar. Entonces, por más interesante que puedan ser sus análisis, no tienen mucho que decir acerca de lo que se hace, se cree y se vive.

El segundo elemento catalizador en la democratización de la cultura es el desarrollo tecnológico y las posibilidades de comunicación que internet y las redes sociales han generado, ya que, mediante ellas, es 
posible salir del acaparamiento de la información que tienen los medios de poder, pudiendo ampliar los canales y espectros de comunicación, generando, consecuentemente, una apertura del debate (cf. Ruiz 66).

Además de la visibilización de sucesos, noticias o acontecimientos censurados por el monopolio comunicacional existente, internet permite abrir un circuito alternativo con diversidad de formatos para difundir el arte, la cultura y los saberes. Es decir, el libro deja de ser el objeto preferente para transmitir conocimiento y se empieza a recurrir a canciones, vídeos, afiches, etc., que se vuelven mecanismos de concientización y politización que logran llegar a un "público" mucho más amplio y diverso. De este modo, como menciona De Sousa: "Los jóvenes están politizados sí, pero de otra manera a la nuestra. Lo están a través del rap, del hip hop, de la música, de las redes sociales" (47)5.

Teniendo a la vista estos elementos y considerando que, como se mencionaba, el lugar ${ }^{6}$ de ejercicio de esta intelectualidad militante es el de la organización popular, a la que no se va de visita como asesor externo sino que se la construye cotidianamente como una praxis transformadora, resulta indispensable establecer algunas características de los colectivos en los cuales se generan estos teóricos. ¿A qué apuntan estas organizaciones? ¿Por qué se gestan? ¿Cuál es su particularidad? Primero, hay que tener presente el contexto en el que éstas surgen, es decir, las décadas de los 80 y 90; una coyuntura en la que, ya sea para enfrentar a las Dictaduras o para hacer frente al giro neoliberal que se profundiza en la etapa postdictatorial, comienzan a aflorar nuevas asociatividades populares, que apuntaban a rearticular el tejido social dañado a partir del despliegue de diversas experiencias de desobediencia y rebeldía que, frente al silencio, la incompetencia y/o el asistencialismo gubernamental, deciden cons-

5 Esto no quiere decir que la apertura tecnológica no tenga riesgos. Tal como establece Enzo Traverso, esto va desde la difusión de mentiras hasta las lógicas alienantes e individualistas que, a través de ésta, se puedan desplegar. Todos estos son elementos que hay que tener a la vista (cf. 100).

6 Aun cuando existen algunos sujetos que trabajan en los espacios universitarios además de su trabajo organizativo militante. Es preciso señalar, sin embargo, que estos son casos excepcionales. 
truir por sí mismos y mismas alternativas populares en los barrios (cf. Olivero \& Tillet). Esto implicó la urgente necesidad de establecer redes -de "enredarse"-desde lo individual, entramando los recursos que permitieran subsistir, y potenciándose en esa urdimbre para resistir y construir alternativas, generando organizaciones de diverso tipo (los piños, los colectivos, etc.); o desde lo plural, entretejiéndose junto a otras organizaciones, creando movimiento, apostando a que el atomismo y ensimismamiento no ayuda a avanzar y hace a las organizaciones más vulnerables a las estrategias desarticuladoras del poder. El aislamiento reduce a la impotencia y al fatalismo, y, por el contrario, el encuentro con otras, la articulación y organización en pos de un horizonte común reanima y vigoriza. El enredo, entonces, se vuelve una manera de autoproducirse en la que los espacios organizativos se vuelven el lugar donde "cada quien opina, cada quien participa en las decisiones, cada quien actúa, en función del interés común y los anhelos compartidos" (Peralta 24).

La organización, como una red que contiene y potencia. Por eso, como todo tejido, es una instancia que se construye desde la diversidad de cada una de las hebras que la componen, las cuales, en apariencia, dan la sensación de una totalidad homogénea, pero que, si se percibe con atención, permite constatar la multiplicidad de nudos, texturas, cruces, consistencias e intensidades que la constituyen; estas por sí solas no resisten mucho, pero en ese entramado con otras forjan solidez y cohesión. Es decir, en la colectividad se han empoderado.

Con las organizaciones se busca inventar nuevos modos de incidir en la política teniendo como principios la autonomía y la horizontalidad (cf. Colectivo Situaciones 2004 71), dispersando los centros de poder, autogestionando las vidas, proyectos y necesidades, y potenciando a los sujetos y sujetas que se hacen partícipes en dicho proceso. Por eso son espacios de ensayo y creatividad, donde se fragua contrapoder o poder popular.

A partir de estos encuentros y potencialidades que van surgiendo y asumiéndose, uno de los desafíos que se contraen, sobre todo frente al desencanto y frustración que han generado las transiciones postdictatoriales, es la reconstrucción de una cultura popular. Así, contrario 
a los discursos oficiales respecto de cómo la juventud y la sociedad toda vivía sumida en el apoliticismo o indiferencia, el compromiso de esta tarea pone en evidencia la necesidad de reconstruir una memoria popular, en la que se reconozca a los sujetos y sujetas populares como artífices de sus vidas y de la historia, reapropiándose entonces de su poder social e histórico (cf. Salazar 2006 152).

En esta línea, surgen una serie de organizaciones cuyo nudo articulador es la cultura, y de manera específica la práctica educativa. Un nudo en el que, tan relevante como la relación que se establece entre educadora o educador y las y los educandos, son los saberes que se ponen en juego en dicha relación. Estos saberes no son meros "objetos" o accesorios que se comparten y crean, sino que engendran una propuesta antropológica específica, una visión de mundo, un proyecto de comunidad. Como indica Claudia Korol?: "La educación ha sido -desde el momento de la conquista- y es -hasta la actualidad- una de las armas fundamentales en la creación de consenso a las políticas dominantes. Es también un escenario de disputa de sentido" (349). Desde esa lectura, la creación de saberes se ha vuelto una práctica fundamental en la praxis revolucionaria, sobre todo a partir del imperativo de producir y socializar aquello que nos ayude como pueblo a liberarnos de la opresión y explotación. Así, los colectivos de educación popular, los espacios de autoeducación de los movimientos sociales, los bachilleratos, escuelas libres y bibliotecas populares, se vuelven semilleros, ecosistemas productores de esta nueva generación intelectual militante.

En estos lugares del subsuelo, donde el pensar colectivo se encarna y aprende, se busca hacer síntesis de él, no de manera acabada y ab-

7 Junto a Claudia Korol, creemos que existe una serie de mujeres que se han vuelto referentas de esta apuesta de investigación militante. Entre ellas, probablemente la más famosa por estos tiempos sea Silvia Rivera Cusicanqui; sin embargo, también están Raquel Gutiérrez, Lorena Cabnal, María Galindo, por nombrar solo a algunas, quienes, desde una apuesta explícitamente anticolonialista, anticapitalista y por supuesto antipatriarcal, han visibilizado la construcción de una política en femenino, en la que lo comunitario es prioritario. Precisamente, por la riqueza que tiene el planteamiento de estas luchadoras, esto será abordado en específico en un próximo escrito. 
soluta, sino como una forma de articularlo en torno a las necesidades y proyectos que se van gestando. Se apuesta a salir de la dispersión o fragmentación en la que los saberes prácticos se despliegan, para poder tomar conciencia de ellos e ir forjando una reflexión propia, en función de lo que la práctica y situación demandan, para empoderarse y enfrentar con solidez los dispositivos de dominación que "desde arriba" se imponen. Para lograr esto, hay que nutrirse y recuperar todas aquellas herramientas que puedan ser útiles para el fin comunitario. Es decir, no se desprecian los análisis de los especialistas sobre la situación política, económica y social nacional o internacional. Al contrario, en la medida en que se van resignificando, articulando con las sensibilidades que movilizan, se vuelven un aporte al hacer, lo cual es valorado.

Estas organizaciones, junto a su práctica crítica, se reconocen como herederas de dos exponentes latinoamericanos ineludibles en el reconocimiento y fortalecimiento del pueblo como agente histórico y sujeto protagonista. Ellos son Paulo Freire, junto a su "pedagogía-problematizadora-liberadora", y Orlando Fals Borda, con la propuesta de "investigación-acción-participativa". A partir de los elementos e insumos que sus reflexiones aportan, se ha podido ir reconociendo críticamente los problemas de la época actual (cf. Fauré; Fonseca y Frantz).

Si bien la propuesta de Fals Borda contribuye con elementos para construir una ciencia popular, el aporte freiriano no sólo se inscribe en la esfera de producción de saberes, sino que es asumido como un talante de lucha. De ahí que gran parte de estas organizaciones se reconozcan como espacios donde la educación popular es lo que determina y orienta las acciones a seguir. La educación popular se constituye como una perspectiva política, que va muchísimo más allá de un conjunto de técnicas, volviéndose una forma de vida y militancia mediante la cual los saberes son humanizados y encarnados de modo tal que se va aprendiendo a ser y nacer distintas (cf. Iglesias 2014 5758). La educación popular se vuelve una nueva trinchera de lucha en la cual se van reorientando y reencausando las experiencias previas, aquello que se es y lo que se quiere llegar a ser; las afectividades, sueños y emociones. 
En estrecha relación con esto, desde estos espacios de construcción se afirma que la práctica política en sí misma es una práctica pedagógica. En ella no sólo se gestionan y administran recursos, sino que, a través de su implementación y despliegue, se construyen, visibilizan e "intercambian" conocimientos y saberes a través de una metodología específica -más allá si esta es expresa o no-. Y esto es válido para toda propuesta y acción política, no solamente para las que se gestan desde el subsuelo. La política gubernamental, la de la clase empresarial o la eclesiástica, es posible comprenderla en tanto propuesta pedagógica. Como advierte Sarlengo, "parecieran no querer darse cuenta que Monsanto, Nidera, Barrick Gold, Chevron y el Club de Paris también son pedagogía" (15). Y viceversa. Es decir, así como la política es pedagógica, la práctica educativa también es política. Y quienes trabajan en organizaciones de educación popular están conscientes de ello. Es decir, no se hace educación de modo asistencialista para subsanar un derecho que el Estado ha negado; no se asume la educación popular y su propuesta metodológica porque parezca entretenido sentarse en círculo a discutir, jugar y actuar, o porque se tenga una devoción profunda por los plumones y los "anticuados" papelógrafos. "Asumimos -dicen los educadores- la perspectiva de la educación popular, puesto que entendemos la práctica educativa como acción política y concebimos al conocimiento como herramienta para la lucha y para la construcción de una nueva sociedad" (Olivero y Tillet 6). En esa línea, se reconocen como el brazo educativo del movimiento popular. De ahí que se suma importancia a lo que se hace, pero también al "cómo" se hace. Relata el Colectivo de Sistematización Militante Caracol (2015), de Chile:

somos educadores y educadoras, y, como tales, le damos harto énfasis a planificar y gestionar espacios educativos donde no existan jerarquías, donde seamos todos y todas protagonistas, espacios de democracia directa y con poca chance para el maquineo. Y también le ponemos el cuerpo [...]: la educación no es solo racional, es también emocional, subjetiva, es corporal. Por eso, cuando uno pasa por fuera de un taller, muchas veces ve gente que no está en la posición "clásica" de una clase, sino también en movimiento. 
Se tiene la convicción de que la lucha es profundamente simbólica; por ello, permanentemente se buscan nuevos modos -los propios- para construir palabras y conceptos que nombren lo que se hace y se es, $y$, con ello, atacar la ofensiva hegemónica que ningunea los términos, experiencias y reflexiones propias. Por eso, se busca construir saberes, narrarse, problematizarse, poniendo de manifiesto pistas o huellas de una nueva sociabilidad en ejercicio. El desafío es crear saberes a partir de la propia práctica.

Toda práctica o experiencia produce saberes. El habitar en el mundo, en la medida que va desarrollándose, implica la adquisición de aprendizajes. Desde el error o el acierto, se sabe que reaccionar de este modo en una determinada situación funciona, pero que en otras pasa lo contrario. Aun cuando no se esté consciente de ello, por el mero actuar en la realidad se va "sabiendo" qué hacer. Como dice Freire: "Cualquiera que sea el nivel en que se da la acción del hombre sobre el mundo, esta acción comprende una teoría" (42). Y es más, si se asume una práctica específica permanentemente, los saberes respecto de ella van aumentando, pues se van descubriendo otras condicionantes o variabilidades que tiene; o en los ámbitos de ella que cada uno se desenvuelve mejor o les resultan más fáciles en función de sus habilidades; se descubre cuánto resiste y por dónde flaquea; qué tipo de vicios y potencialidades tiene, etc. Así, en la práctica misma, es posible volverse "experto", pero si no se logra "saber que sabemos" y no se comunica ni comparte, no se avanza. Ya que cuando aquél súper experimentado en un hacer específico no esté, se tendrá que comenzar desde el principio. Por ello la necesidad de teorizarse y reflexionarse; como dice el Colectivo Caracol (2014): "el que hace sabe, pero el que piensa lo que hace, hace mejor".

En el escenario actual y buscando potenciar los espacios de resistencia, la necesidad de auto-investigarse es fundamental. Así, es posible recuperar saberes que vienen de experiencias de lucha previa, reinterpretar aquellos que llegan desde la academia y generar nuevos desde el hacer. Para eso se han desarrollado "armas epistémicas", tales como la sistematización, la investigación militante, la investigación acción participativa, las cuales buscan articular implicancia y pensamiento (cf. 
Colectivo Situaciones 2004 97). Este es el criadero de intelectuales, de ahí que el lugar de enunciación de ellos sea siempre la praxis (cf. Mazzeo 77). Se producen desde la praxis para mejorarla y ampliar los horizontes de acción política. Y estas reflexiones no son abstracciones que se materializan en tratados o manifiestos lógicamente argumentados. Las respuestas y apuestas deben verificarse en la misma experiencia, lo que no significa establecer una relación utilitarista con ella, ya que no es un medio para lograr el fin (la consolidación de una teoría), sino todo lo contrario: la reflexión es un medio para inteligir, mejorar y fortalecer el fin, es decir, la práctica política revolucionaria. Como mencionan los situacionistas, "No se pretende utilizar las experiencias como campo de confirmación de las hipótesis de laboratorio, sino de establecer un vínculo positivo con los saberes subalternos, dispersos y ocultos, para producir un cuerpo de saberes prácticos de contrapoder" (Colectivo Situaciones 2001 39).

La creación de poder popular es fruto de un proceso profundamente pedagógico que implica, para empezar, un diagnóstico participativo de la situación. En función de este se programan acciones a seguir que, luego, serán realizadas. Entonces, se hace una evaluación colectiva que tiene a la vista las etapas anteriores. Pero esto no termina acá. Una vez que se ha llegado a este punto, lo que sucede es que se vuelve a empezar. Es decir, diagnóstico-acción-evaluación es un proceso que se extiende hasta el infinito, y que se vuelve una exigencia cada vez que se emprende una praxis comunitaria que busque empoderar a los sujetos y sujetas (cf. Peralta 14). La única diferencia es que, si estos procesos van siendo sistematizados, cuando se vuelva a comenzar, ya no se parte desde una base de intuiciones, sino que se tiene un respaldo, un punto de partida que no es ajeno a la colectividad, sino que es parte de la propia historia, de la memoria y de la ciencia popular. De ahí la necesidad de rescatar esos saberes que ya se han venido construyendo, aquellos saberes del buen vivir, saberes ancestrales que se vinculan con la creación de colectividad, con recuerdos y experiencias de organización gestadas a contrapelo de la oficialidad, en la marginalidad de las urbes, exiliadas de las noticias y de los grandes textos, en las fisuras de la historia y del conocimiento hegemónico. Son saberes preñados del hacer 
y situación, inundados de acción política -por eso son perseguidos y despreciados por los espacios de poder (cf. Machado \& Zibechi 168)-. Son reflexiones que permiten leerse como pueblo organizado, no sólo para constatar lo que se es, sino para construir el cómo se quiere que sea. Por ello están colmados de una actitud crítica, cuestionadora y creadora. Son reflexiones útiles para resistir y, por ello, no se forjan buscando responder a los protocolos o cánones académicos, sino que configuran el saber popular como parte de las armas de resistencia y gestión alternativa (cf. Korol 355).

La construcción de saberes y cultura "desde abajo" no es un movimiento exclusivamente intelectivo, sino que se da entrelazado con la construcción de una nueva propuesta de vida y de relaciones entre sujetos y sujetas. Y se está consciente de que, como cualquier otra perspectiva epistémica, ésta también implica una concepción ideológica determinada. Es una apuesta por el empoderamiento y la transformación de sujetos. Por eso es que el intelectual militante, el educador popular y las sistematizadoras son sujetos y sujetas que construyen espacios de resistencia. No son sujetos externos que trabajan "con", "para" o "sobre" el movimiento popular, sino que son partícipes y constructores de ese mundo otro. Frente a esto, establece Raúl Zibechi (2011b):

Dirán que se pierde la distancia necesaria para poder ejercer la crítica. En este punto hay una diferencia fundamental, que tiene que ver con la forma como se elabora conocimiento: desde dónde y en qué circunstancias se habla, se piensa, se escribe. Hay dos opciones. O los de abajo son excusa para que otros hagan política o elaboren tesis, o una y otra se elaboran en minga, en trabajo comunitario, con los abajos (57).

\section{A modo de cierre (y apertura)}

A partir de lo expuesto, es posible poner en valor que la riqueza de Nuestra América no sólo se reduce a su diversidad de paisajes, alimentos, pieles y danzas, sino que su fortaleza sigue estando presente en las 
prácticas de resistencia que, a pulso y desde abajo, se han construido a lo largo de la historia, y que hoy siguen forjándose.

Una nueva generación de militantes que ha asumido en sus manos la disputa epistémica, educativa y cultural emerge desde sus entrañas, desbordando lentamente los cauces institucionales que siguen imponiendo un modelo de saber cómplice de las lógicas capitalistas, patriarcales y colonialistas. Sin duda el análisis de las características, formatos y referentes que configuran esta praxis militante intelectiva dan para mucho más; por lo mismo, quedan pendientes, y han de ser trabajadas en otros lugares.

\section{Bibliografía}

Benasayag, Miguel. "Fundamentos para una 'meta-economía'". Contrapoder, una introducción. VVAA, Buenos Aires: Ediciones de Mano en mano: 2001.

Borón, Atilio. "Si hay un rasgo que marca al imperialismo contemporáneo es la enorme proliferación de sus mecanismos de dominación cultural". Por la izquierda. Veintidós testimonios a contracorriente. Tomo I, ed. Ubieta Enrique. La Habana: Ediciones ICAICC y Editorial José Martí, 2007.

Campione, Daniel. "Hay que reivindicar la idea militante del intelectual". ¿Intelectuales entre preguntas?, ed. Sarlengo A. Argentina: Editorial Del Castillo, 2014.

Ceceña, Ana. "La subversión política del zapatismo". América Libre 20, VVAA. Buenos Aires: América Libre, 2003.

Colectivo Caracol. ¿Qué es sistematizar? Recuperado de: https://www.youtube.com/watch?v=t0Yxj515reo, 2014.

Colectivo Caracol. "Entrevista a Carola la caracola, integrante del Colectivo de Sistematización Militante CARACOL". Revista Rufián, Vol. 22, Ahora somos. Construcciones de poder popular (2015). Recuperado de http://rufianrevista. org/category/22/

Colectivo Situaciones. "Por una política más allá de la política". Contrapoder, una introducción, VVAA. Buenos Aires: Ediciones de Mano en mano, 2001.

Colectivo Situaciones. "Algo más sobre la investigación militante. Notas al pie sobre procedimientos e (in)decisiones". Nociones comunes, experiencias y ensayos entre investigación y militancia. Malo Marta. Madrid: Editorial Traficante de Sueños, 2004. 
Colectivo Situaciones. Conversaciones en el Impasse. Dilemas políticos del presente. Buenos Aires: Editorial Tinta Limón, 2009.

De Sousa, Boaventura. "Más allá del pensamiento abismal: de las líneas globales a una ecología de saberes". Epistemologías del Sur (perspectivas), eds. De Sousa, Boaventura y María Meneses. España: AKAL, 2014.

Dussel, Enrique. 20 tesis sobre política. México: Siglo XXI, 2006.

Fauré, Daniel. Prácticas autoeducativas de la juventud Urbano popular en el Chile postdictatorial: Saberes, control comunitario y poder popular territorial (Santiago, 1987- 2013). (Tesis para optar al grado de Doctor en Historia, Mención Historia de Chile). Santiago, Chile: Universidad de Chile, 2015.

Fonseca, Elsa y Frantz, Walter. "Sistematización, creación de conocimiento, epistemologías no eurocéntricas". América Latina en movimiento: Educación popular: vigencia y desafíos, VVAA. Ecuador: Alai y Ceaal coeditores, 2014.

Freire, Paulo. ¿Extensión o comunicación? La concientización en el medio rural. México: Siglo XXI, 1984.

Gómez, Ramón. "La lógica operativa del neoliberalismo extractivista. Vínculos no convencionales". Periódico Rebelión, 15/10/2013 Recuperado de: http:// argentina.indymedia.org/news/2013/10/848569.php 2013

Harvey, David. El Nuevo Imperialismo. Madrid, España: Akal, 2004.

Holloway, John. "Doce tesis sobre el antipoder". Contrapoder, una introducción, VVAA. Buenos Aires: Ediciones de Mano en mano, 2001.

Holloway, John. Acerca de la revolución. Buenos Aires: Ed. Capital Intelectual, 2012.

Iglesias, Mónica. "Teoría en movimiento: más de una década de pensamiento crítico". OSAL, Vol. XII, N 30, Buenos Aires, Argentina: CLACSO (2011).

Iglesias, Roberto. Un viaje hacia la autonomía. Un recorrido sobre los conceptos y procesos de organización de la educación popular en Argentina. Córdoba: UniRío editora, 2014.

Korol, Claudia. "La Educación Popular en la batalla contra las muchas colonizaciones". Resistencias populares a la recolonización del continente. Segunda Parte, ed. Korol, Claudia. Buenos Aires: América Libre, 2010.

Machado, Decio y Zibechi, Raúl. Cambiar el mundo desde arriba. Los límites del progresismo. Santiago: Editorial Quimantú, 2016.

Mazzeo, Miguel. Conjurar a Babel. La nueva generación intelectual argentina a diez años de la rebelión popular de 2001. Buenos Aires: Editorial El Colectivo, 2012. 
Olivero, Laura y Tillet, Agustín. Entre el/la educador/a popular y el/la investigador/amilitante. La apuesta del Centro de Investigación Soldati en la Ciudad Autónoma de Buenos Aires. XI Jornadas de Sociología. Facultad de Ciencias Sociales, Buenos Aires: Universidad de Buenos Aires, 2015.

Peralta, Hernán. Luces en la ruta del poder popular. Sucre, Venezuela: sin editorial: sin fecha.

Ruiz, Carlos. "Notas sobre los intelectuales y el espacio público en el sistema cultural actual". Anales de la Universidad de Chile. El rol de los intelectuales públicos en la sociedad actual. VVAA Séptima Serie, №9 (2015). Santiago: Universidad de Chile. Salazar, Gabriel. "La Historia como Ciencia Popular: despertando a los 'weupifes". Revista Austral de ciencias sociales, Vol. 11, Chile (2006).

Salazar, Gabriel. En el nombre del poder constituyente (Chile, siglo XXI) Santiago: Lom, 2011.

Salazar, Gabriel. Del poder constituyente de asalariados e intelectuales (Chile, siglos XX y XXI). Santiago: Lom, 2012.

Tapia, Luis. Política Salvaje. La Paz, Bolivia: Coedición CLACSO, Muela del Diablo, Comunas, 2008.

Traverso, Enzo. ¿Qué fue de los intelectuales? Conversación con Régis Meyran. María de la Paz Georgiadis (trad.). Buenos Aires: Siglo XXI editores, 2014.

Zibechi, Raúl. Autonomías y emancipaciones: América latina en movimiento. Lima: Universidad Nacional Mayor de San Marcos, Fondo editorial de la facultad de Ciencias Sociales; 2007.

Zibechi, Raúl. Territorios en resistencia. Cartografía Política de las periferias urbanas latinoamericanas. Santiago, Chile: Editorial Quimantú, 2009.

Zibechi, Raúl. "El pensamiento crítico en el laberinto del progresismo", en OSAL, Vol. XII, N 30, noviembre. Buenos Aires, Argentina: CLACSO (2011a).

Zibechi, Raúl. "La ética necesita un lugar otro para echar raíces y florecer, Intercambio epistolar sobre ética y política", en Revista Rebeldías, № 77. Recuperado de http://revistarebeldia.org/ 2011b 